\title{
SERVISI PLAĆENE TELEVIZIJE U SISTEMIMA DIGITALNE ZEMALJSKE TELEVIZIJE U EVROPI
}

\author{
Siniša llić ${ }^{1}$ \\ Branimir Jakšić ${ }^{1}$ \\ Slobodan Bojanić ${ }^{2}$, \\ Ranko Babić ${ }^{1}$, \\ Mile Petrović ${ }^{1}$ \\ ${ }^{1}$ Fakultet tehničkih nauka, \\ Univerzitet u Prištini, \\ Kosovska Mitrovica, Srbija \\ ${ }^{2}$ ETSI Telecomunicacion, \\ Universidad Politecnica de Madrid, \\ Spain
}

Correspondence:

Branimir Jakšić

e-mail:

branimir.jaksic@pr.ac.rs

\begin{abstract}
:
U ovom radu dat je pregled servisa plaćene televizije (PAY TV) u okviru digitalne zemaljske televizije u Evropi. Najpre su za sve evropske zemlje date karakteristike „slobodne” (free-to-air) zemaljske TV koje uključuju: broj zauzetih multipleksa, standard za DTV (DVB-T i DVB-T2), standard za video-kompresiju i broj SDTV i HDTV kanala u multipleksima. Zatim je dat pregled osnovnih karakteristika za PAY TV, kao i osnovne tehničke specifikacije koje koriste provajderi za emitovanje PAY TV. Grafički je prikazano poređenje broja SDTV i HDTV kanala koji se emituju u free-to-air i PAY TV sistemima kao zastupljenost DVB-T i DVB-T2 standarda za sve evropske zemlje.
\end{abstract}

Key words:

slobodna TV, plaćena TV, DVB-T, DVB-T2, MPEG.

\section{UVOD}

Na Regionalnoj konferenciji o radio-komunikacijama (RRC-06), u organizaciji Međunarodne unije za telekomunikacije (ITU), u periodu od 15. maja do 16. juna 2006. godine u Ženevi, usvojena su Završna akta u kojima je sadržan novi sporazum Ženeva 2006 (GE06) koji omogućava uvođenje potpunog digitalnog zemaljskog radiodifuznog emitovanja u zoni planiranja. Sve evropske zemlje obavezale su se da najkasnije do 17. juna 2015. godine pređu na digitalno emitovanje radio i televizijskog signala, odnosno izvrše analog switch off (ASO). U skoro svim zemljama Evrope danas se isključivo emituje digitalna zemaljska televizija. Uvođenjem digitalnog i isključivanjem analognog emitovanja oslobađa se veći deo radio spektra, čime se omogućuje emitovanje većeg broja TV programa i pratećih servisa. Jedna od prednosti digitalnog emitovanja je i distribucije plaćene TV (PAY TV) u zemaljskoj DVB-T mreži, tzv. „bežična kablovska TV”.

Razvojem digitalne televizije omogućena je, pored standardne digitalne televizije (SDTV - Standard Definition Television), upotreba i televizije visoke rezolucije HDTV (High Definition Television). HDTV je tehnologija koja nudi kvalitet slike i zvuka značajno višeg u odnosu na tradicionalne tehnologije prikaza slike i zvuka. Televizija Ultra visoke definicije (UHDTV - Ultra High Definition Television) uključuje 4K UHDTV (2160p) i 8K UHDTV (4320p), i predstavlja unapređenu verziju HDTV [1]. 
Evropske zemlje usvojile su standard DVB-T (Digital Video Broadcasting - Terrestrial), odnosno DVB-T2. Prvi koncepti DVB-T usvojeni su 1993. a prva finalna verzija 1997. godine. Podrazumeva prenos digitalizovanog audio i video sadržaja zemaljskim putem posredstvom emisione tehnologije u VHF i UHF opsegu uz pomoć konvencionalnih sistema predajnika i odgovarajućih prijemnika $[2,3]$. DVB-T2 je naprednija verzija DVB standarda za terestrijalno emitovanje. U poređenju sa DVB-T, DVB-T2 nudi značajno manju osetljivost na smetnje i šumove i obezbeđuje 30-50\% veći protok podataka, što je naročito pogodno za HDTV (High-definition television) [2, 3].

Kako zauzetost frekvencijskog spektra zavisi od bitskog protoka, potrebno ga je smanjiti, pa se vrši redukcija, odnosno kompresija signala korišćenjem više metoda. Najšire primenjivan standard za kompresiju u digitalnoj televiziji je MPEG-2, nakon kojeg se pojavio MPEG-4 (verzija 10), odnosno H.264/AVC. Dodato je nekoliko poboljšanja koja se ogledaju u novim načinima kodiranja i smanjivanju bitskog protoka bez degradacije kvaliteta slike. Najnoviji video-kompresioni standard HEVC/H.265 video-kodiranje (High Efficiency Video Coding) donosi bolje performanse nego prethodni standardi kodiranja, a najveća prednost novog standarda je do 50\% efikasnija kompresija u odnosu na H.264 i podrška za $4 \mathrm{~K}$ i $8 \mathrm{~K}$ UHDTV rezoluciju [4].

\section{SLOBODNA ZEMALJSKA TELEVIZIJA}

Slobodna ili free-to-air (FTA) zemaljska televizija odnosi se na distribuciju digitalne televizije i pratećih servisa bez dodatne naknade.

U Tabeli 1 date su osnovne karakteristike u vezi sa primenom DVB-T standarda u zemljama Evrope. Dat je broj SDTV i HDTV kanala dostupnih u multipleksima zemaljske digitalne TV. Broj kanala odnosi se na nacionalne kanale, tj. kanale koji pokrivaju celu teritoriju države. Dat je i broj nacionalnih multipleksa (MUX), lokalni nisu predstavljeni.

Prikazani su i standardi sa video-kompresijama koji se koriste u različitim državama, kao i godine kada je započela digitalna zemaljska TV transmisija i godina kada je izvršen ASO (analog switch off). Godina početka emitovanja DVB-T odnosi se na eksperimentalno emitovanje, dok je regularno i komercijalno emitovanje započelo kasnije. Podaci prikazuju stanje na dan 1. januar 2017. godine, a prikupljeni su sa zvaničnih veb-stranica nacionalnih regulatornih agencija i provajdera digitalne zemaljske transmisije za određenu zemlju [5-51].

\begin{tabular}{|c|c|c|c|c|c|c|}
\hline Zemlja & SD & HD & MUX & Standard/Video-kompresija & Start & ASO \\
\hline Albanija & - & - & - & - & 2004. & \\
\hline Andora & 28 & - & 6 & DVB-T/MPEG-2 & 2005. & 2007. \\
\hline Austrija & 5 & 7 & 3 & $\begin{array}{c}\text { DVB-T/MPEG-2 } \\
\text { DVB-T2/MPEG-4 (za HDTV) }\end{array}$ & 2004. & 2011. \\
\hline Belorusija & 9 & - & 1 & DVB-T/MPEG-4 & 2004. & \\
\hline Belgija & 7 & - & 2 & DVB-T/MPEG-2 & 2002. & 2010. \\
\hline $\begin{array}{c}\text { Bosna i } \\
\text { Hercegovina }\end{array}$ & 3 & - & 1 & DVB-T/MPEG-4 & 2016 & \\
\hline Bugarska & 5 & 1 & 1 & DVB-T/MPEG-4 & 2004. & 2013. \\
\hline Crna Gora & 5 & - & 1a & DVB-T2/MPEG-4 & 2014. & 2015. \\
\hline Češka Republika & 24 & 7 & 4 & $\begin{array}{c}\text { DVB-T/MPEG-2 } \\
\text { DVB-T2/MPEG-4 (za HDTV) }\end{array}$ & 2000. & 2012. \\
\hline Danska & 3 & 6 & 2 & DVB-T/MPEG-4 & 2003. & 2009. \\
\hline Estonija & 9 & 2 & 4 & $\begin{array}{c}\text { DVB-T/MPEG-4 } \\
\text { DVB-T2/MPEG-4 (za HDTV) }\end{array}$ & 2004 . & 2010. \\
\hline Finska & 21 & 4 & 3 & $\begin{array}{c}\text { DVB-T/MPEG-2 } \\
\text { DVB-T2/MPEG-4 (za HDTV) }\end{array}$ & 1999. & 2007. \\
\hline
\end{tabular}




\begin{tabular}{|c|c|c|c|c|c|c|}
\hline Francuska & 3 & 24 & 5 & $\begin{array}{c}\text { DVB-T/MPEG-2 } \\
\text { DVB-T/MPEG-4 (za HDTV) } \\
\text { DVB-T2 testovi }\end{array}$ & 2005. & 2011. \\
\hline Grčka & 12 & 1 & 3 & DVB-T/MPEG-4 & 2006. & 2014. \\
\hline Holandija & 3 & - & 1 & DVB-T/MPEG-2 & 1998. & 2006. \\
\hline Hrvatska & 11 & - & 3 & DVB-T/MPEG-2 & 2002. & 2010. \\
\hline Island & 7 & 1 & 1 & DVB-T/MPEG-4 & 2005. & 2015. \\
\hline Irska & 8 & 2 & 2 & DVB-T/MPEG-4 & 2006. & 2012. \\
\hline Italija & 139 & 13 & 18 & $\begin{array}{c}\text { DVB-T/MPEG2, MPEG } 4 \\
\text { DVB-T2 testovi }\end{array}$ & 1998. & 2008. \\
\hline Kipar & 15 & 1 & 3 & DVB-T/MPEG-4 & 2010. & 2011. \\
\hline Letonija & 5 & - & 1 & DVB-T/MPEG-4 & 2002. & 2010. \\
\hline Litvanija & 14 & - & 2 & DVB-T/MPEG-4 & 2003. & 2012. \\
\hline Luksemburg & 10 & - & 3 & DVB-T/MPEG-2 & 2002. & 2006. \\
\hline Mađarska & 7 & 5 & 1 & DVB-T/MPEG-4 & 2004. & 2013. \\
\hline Makedonija & 9 & 1 & 3 & DVB-T/MPEG-4 & 2004. & 2013. \\
\hline Moldavija & 8 & - & 1 & DVB-T2/MPEG-4 & 2003. & \\
\hline Nemačka & 28 & - & 5 & $\begin{array}{c}\text { DVB-T/MPEG-2 } \\
\text { DVB-T2/HEVC switch }\end{array}$ & 2002. & 2012. \\
\hline Norveška & - & - & - & - & 1999. & 2009. \\
\hline Poljska & 25 & 2 & 4 & DVB-T/MPEG-4 & 2001. & 2013. \\
\hline Portugal & 7 & 1 & 1 & DVB-T/MPEG-4 & 2009. & 2012. \\
\hline Rumunija & 8 & 1 & 1 & DVB-T2/MPEG-4 & 2005. & \\
\hline Rusija & 20 & - & 2 & $\begin{array}{c}\text { DVB-T2/MPEG-4 } \\
\text { DVB-T2/HEVC testovi }\end{array}$ & 2005. & \\
\hline Slovačka & 14 & 2 & 3 & $\begin{array}{c}\text { DVB-T/MPEG-2 } \\
\text { DVB-T/MPEG-4 (za HDTV) }\end{array}$ & 2009 . & 2012. \\
\hline Slovenija & 9 & 2 & 2 & DVB-T/MPEG-4 & 2001. & 2010. \\
\hline Srbija & 10 & - & 2 & DVB-T2/MPEG-4 & 2005. & 2015. \\
\hline Španija & 23 & 9 & 8 & $\begin{array}{c}\text { DVB-T/MPEG-2 } \\
\text { DVB-T/MPEG-4 (za HDTV) }\end{array}$ & 1999. & 2010. \\
\hline Švedska & 7 & 2 & 1a & $\begin{array}{c}\text { DVB-T/MPEG-2 } \\
\text { DVB-T2/MPEG-4 (za HDTV) }\end{array}$ & 1999. & 2007. \\
\hline Švajcarska & 7 & - & 3 & DVB-T/MPEG-2 & 2000. & 2008. \\
\hline Ukrajina & 27 & 1 & 4 & DVB-T2/MPEG-4 & 2007. & \\
\hline Velika Britanija & 79 & 15 & 8 & $\begin{array}{l}\text { DVB-T/MPEG-2 } \\
\text { DVB-T2/MPEG-4 }\end{array}$ & 1998. & 2012. \\
\hline
\end{tabular}

a.Multipleks se koristi i za PAY TV

Tabela 1. Osnovne karakteristike FTA digitalne zemaljske TV transmisije u zemljama Evrope 
Iz Tabele 1 može se videti da samo manji broj zemalja (Albanija, Bosna i Hercegovina, Belorusija, Moldavija, Rumunija, Rusija i Ukrajina) nisu izvršili poptpuni prelazak na digitalno TV emitovanje. Takođe, može se videti da u dve zemlje (Albanija i Norveška) ne postoji FTA transmisija, već isključivo PAY TV.

Na Slici 1 dat je grafički prikaz zastupljenosti DVB-T/ T2 standarda i video-kompresionih standarda za FTA u Evropi.

\section{FTA TV}

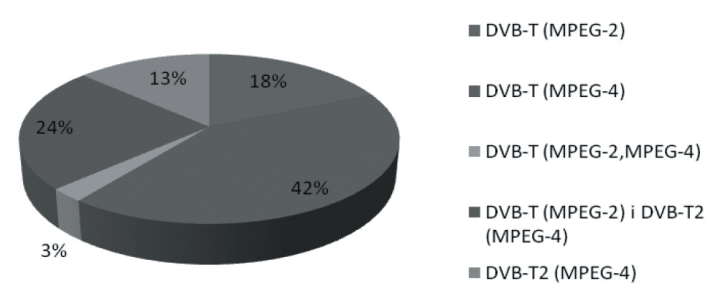

Slika 1. Zastupljenost DVB-T/T2 standarda i videokompresionih standard za FTA TV transmisiju.
Najzastupljeniji standard za FTA transmisiju je DVBT/MPEG-4 (42\%), a zatim paralelna upotreba DVB-T/ MPEG-4 i DVB-T2/MPEG-4 standarda, gde se DVB-T2/ MPEG-4 koristi uglavnom za HDTV.

\section{PLAĆENA ZEMALJSKA TELEVIZIJA}

Plaćena ili PAY zemaljska televizija odnosi se na distribuciju digitalne televizije i pratećih servisa sa nakandom, odnosno uz uslovni pristup servisima. U Tabeli 2 date su osnovne karakteristike u vezi sa primenom DVB-T standarda za PAY TV u zemljama Evrope. Dat je broj SDTV i HDTV kanala dostupnih u multipleksima, kao i broj multipleksa (MUX) koji provajder koristi za PAY TV usluge.

Prikazani su i standardi sa video-kompresijama koji se koriste u različitim državama, kao i godina početka kada je započeta PAY TV i ime provajdera. Podaci prikazuju stanje na dan 1. janaur 2017. godine, a prikupljeni su sa zvaničnih veb-stranica nacionalnih provajdera PAY TV digitalne zemaljske transmisije za određenu zemlju [5, 6, $9,10,15,17-19,21,23,25,26,29-31,34,35,38,43,46,48]$.

\begin{tabular}{|c|c|c|c|c|c|}
\hline Zemlja & SD & HD & MUX & Standard & Start \\
\hline Albanija & 62 & 9 & 8 & DVB-T2/MPEG-4 & 2004. \\
\hline Austrija & 23 & 7 & 3 & DVB-T2/MPEG-4 & 2013. \\
\hline Belorusija & 34 & - & 2 & DVB-T2/MPEG-4 & 2011. \\
\hline Crna Gora & 29 & - & 2 & DVB-T2/MPEG-4 & 2016. \\
\hline Danska & 13 & 17 & 4 & DVB-T2/MPEG-4 & 2009. \\
\hline Estonija & 30 & - & 2 & DVB-T/MPEG-4 & 2009. \\
\hline Finska & 44 & 12 & 6 & $\begin{array}{l}\text { DVB-T/MPEG-2, } \\
\text { DVB-T2/MPEG-4 }\end{array}$ & 2006. \\
\hline Francuska & 7 & 1 & 1 & DVB-T/MPEG-4 & 2005. \\
\hline Holandija & 27 & - & 4 & DVB-T/MPEG-2 & 2004. \\
\hline Hrvatska & 43 & 2 & 2 & DVB-T2/MPEG-4 & 2012. \\
\hline Island & 10 & 2 & 1 & DVB-T/MPEG-4 & 2010. \\
\hline Italija & 27 & 8 & 5 & DVB-T/MPEG-2, MPEG-4 & 2005. \\
\hline Letonija & 46 & 11 & 6 & DVB-T/MPEG-4 & 2009. \\
\hline Litvanija & 31 & 3 & 4 & DVB- /MPEG-4 & 2009. \\
\hline Mađarska & 47 & - & 4 & DVB-T/MPEG-4 & 2008. \\
\hline
\end{tabular}




\begin{tabular}{lccccc}
\hline Makedonija & 41 & - & 4 & DVB-T/MPEG-4 & 2009. \\
\hline Norveška & 30 & 8 & 5 & DVB-T/MPEG-4 & 2009. \\
\hline Slovačka & 14 & 1 & 1 & DVB-T2/MPEG-4 & 2014. \\
\hline Srbija & 23 & - & 1 & DVB-T2/MPEG-4 & 2016. \\
\hline Švedska & 44 & 11 & 6 & DVB-T2/MPEG-4 & 1999. \\
\hline
\end{tabular}

Tabela 2. Osnovne karakteristike PAY digitalne zemaljske TV transmisije u zemljama Evrope.

Iz Tabele 2 vidi se da su prvi servisi zemaljske PAY TV započeli u Švedskoj još 1999. godine. U ostalim zemljama servis je uglavnom započeo nakon potpune digitalizacije, odnosno nakon gašenja anlognog signala. Najveći broj multipleksa za PAY TV aktivirano je u Albaniji, Finskoj, Švedskoj, i Letoniji (po šest), a najmanji broj, po jedan, koristi se u Francuskoj, Slovačkoj i Srbiji.

$\mathrm{Na}$ Slici 2 dat je grafički prikaz zastupljenosti FTA i PAY TV transmisije u zemljama Evrope, a na Slici 3 grafički prikaz zastupljenosti DVB-T/T2 i komresionih standarda za zemaljsku PAY TV transmisiju u evropskim zemljama.

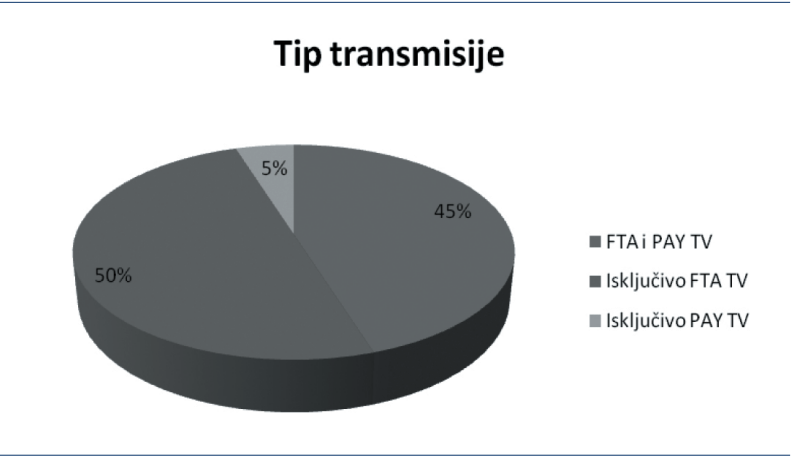

Slika 2. Zastupljenost FTA i PAY TV zemaljske transmisije.

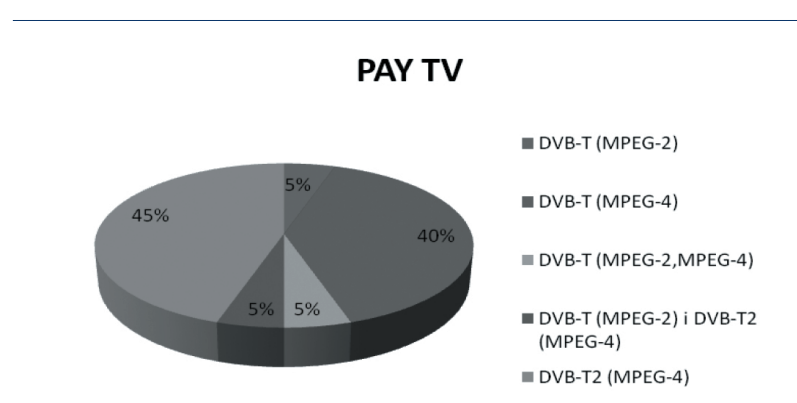

Slika 3. Zastupljenost DVB-T/T2 standarda i videokompresionih standarda za PAY TV transmisiju.
Sa datih slika može se videti da su zemaljski PAY TV servisi prisutni u polovini zemalja Evrope, dok je kao standard za PAY TV najzastupljeniji DVB-T2/MPEG4, odnosno DVB-T/MPEG-4, pre svega zbog uštede u kapacitetu, tj. mogućnosti emitovanja više TV programa u okviru jednog multipleksa. Standard DVB-T/MPEG-2 koristi se uglavnom za free-to-air (FTA). Sve veći broj zemalja koje koriste DVB-T standard planiraju da u skorijoj budućnosti pređu na unapređeni DVB-T2 standard.

Na Slici 4 i Slici 5 dat je grafički prikaz ukupnog broja SDTV i HDTV kanala, respektivno, uključujući i FTA i PAY TV servise koji su dostupni u multipleksima digitalne zemaljske TV. Dat je prikaz za prvih deset zemalja sa najvećim brojem SDTV, odnosno HDTV kanala.

Broj SDTV i HDTV kanala je u direktnoj vezi sa brojem dostupnih multipleksa i i primenjenog DVB-T i kompresionog standarda prikazanih u Tabeli 1 i Tabeli 2. Ubedljivo najveći broj SDTV nacionalnih kanala (166) dostupan je u Italiji, a zatim slede Velika Britanija, Finska i Albanija. Najveći broj HDTV kanala dostupan je u Francuskoj i Danskoj, a zatim slede Italija, Finska i Velika Britanija. U Danskoj je čak i veći broj HDTV kanala u odnosu na SDTV (23 prema 16).

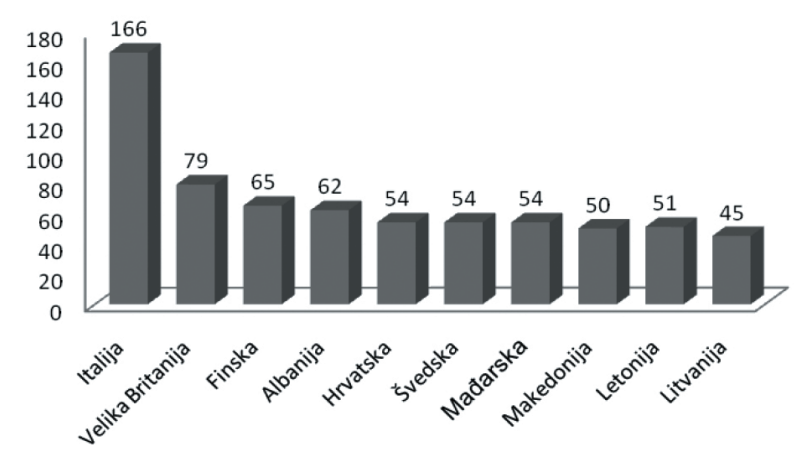

Slika 4. Broj zemaljskih SDTV (FTA+PAY) kanala. 


\section{LITERATURA}

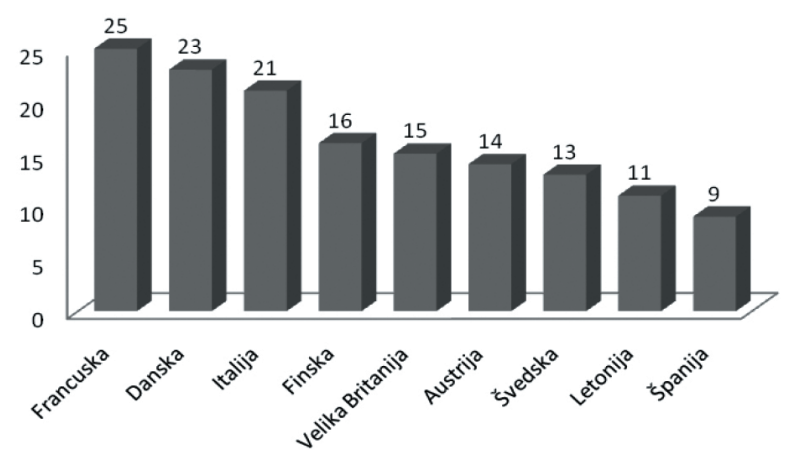

Slika 5. Broj zemaljskih HDTV(FTA+PAY) kanala.

\section{ZAKLJUČAK}

Distribucija plaćenih TV kanala i pratećih servisa kroz zemaljsku mrežu relativno je novi način pružanja servisa, u odnosu na standardne načine distribucije (IPTV, kablovski i satelitski prenos). Prednost ovog načina distribucije, u odnosu na kablovski, jeste u tome što se svi servisi do krajnjih korisnika pružaju bežičnim putem. Zapravo, pružanje usluga plaćene TV zemaljskom transmisijom dobilo je smisao tek nakon digitalizacije zemaljske analogne mreže, čime se oslobađa značajni deo frekvencijskog spektra, i zbog mogućnosti prenosa velikog broja digitalnih TV kanala u jednom analognom TV kanalu. Ovakav način pružanja servisa digitalne televizije prisutan je u polovini evropskih zemalja, a izuzetno je razvijen u skandinavskim i baltičkim zemljama.

Povećanja broja TV usluga kroz digitalnu zemaljsku mrežu ostvariće se prelaskom na unapređeniji standard za digitalnu TV - DVB-T2/MPEG-4. Polovina evropskih zemalja već koristi ovaj standard, dok su ostale u procesu tranzicije ili planiraju skoriji prelazak na unapređeni DVB-T2 standard sa MPEG-4, ili čak HEVC kompresijom. Primena DVB-T2 standarda omogući će transmisiju većeg broja TV kanala u okviru jednog multipleksa, a pre svega omogući će povećanje broja HDTV kanala. Testovi sa HEVC kompresijom danas su prisutni u Nemačkoj i Rusiji [37, 42].

\section{ZAHVALNOST}

Ovaj rad rađen je u okviru projekta Implementation of the study program - Digital Broadcasting and Broadband Technologies (DBBT Master studies), Erasmus+ CBHE Project No. 561688-EPP-1-2015-1-XK-EPPKA2CBHE-JP.
[1] B. Jaksic, M. Petrovic, I. Milosevic, R. Ivkovic and S. Bjelovic, "UHDTV into Terrestrial and Satellite Systems," in Proceedings of International Scientific Conference UNITECH 2015, Gabrovo, Bulgaria, pp. II112-II118, November 2015

[2] DVB Project: http://www.dvb.org

[3] M. Petrović, B. Jakšić, I. Milošević, V. Trifunović and B. Gara, "Pregled DVB-T u zemljama bivše Jugoslavije," Zbornik radova XII međunarodnog naučno-stručnog simpozijuma INFOTEH 2013, Jahorina, Bosna i Hercegovina, vol. 12, pp. 354-359, mart 2013.

[4] B. S. Jaksic and M. B. Petrovic, Implementation of Video Compression Standards in Digital Television, Chapter 9 in Recent Advances in Image and Video Coding, Rijeka: InTech, 2016.

[5] DigitAlb: http://digitalb.al

[6] Tring TV: http://www.tring.al

[7] Servei de Telecomunicacions d'Andorra (STA): http://www.andorratelecom.ad/

[8] DVB-T Austria: http://www.dvb-t.at/

[9] Simpli TV: https://www.simplitv.at

[10] Zala TV: http://zala.by

[11] Conseil Supérieur de l'Audiovisuel (CSA): http:// www.csa.be/

[12] Regulatorna agencija za komunikacije BiH: http:// rak.ba/bos/

[13] Commission for Communications Regulation (CRC): http://www.crc.bg/

[14] Predajnici i veze: www.rdc.co.me

[15] TV za sve: http://www.tvzasve.me

[16] Cesky Telekomunikacni (CTU): http://www.ctu.cz

[17] Boxer TV Denmark: www.boxertv.dk/

[18] Levira: www.levira.ee

[19] Digita: www.digita.fi/

[20] TéléDiffusion de France: http://www.tdf.fr/

[21] TNT Terrestre: http://www.telesatellite.com/television-numerique-terrestre/

[22] http://www.digea.gr

[23] Digitenne: https://www.digitenne.nl/

[24] Odasiljaci i veze (OiV): http://www.oiv.hr/

[25] Evo TV: http://www.evotv.hr/

[26] Digital Iceland: http://www.vodafone.is/sjonvarp/

[27] Commission for Communications Regulation (COMREG): http://www.comreg.ie/

[28] Autorita per le Garanzie nelle Comunicazioni (AGCOM): http://www.agcom.it/

[29] Mediaset Premium: http://www.mediasetpremium.it/ 
[30] Lat Telecom: http://www.lattelecom.lv/

[31] Telia: https://www.telia.lt/

[32] Institut Luxembourgeois de Régulation (ILR): www. ilr.public.lu/

[33] Antenna Hungária: http://ahrt.hu/

[34] MinDig TV: http://mindigtv.hu/

[35] Vip TV Lite: https://www.vip.mk/

[36] Radiocomunicații Moldova: http://radiocom.md

[37] DasÜberallFernsehen: http://www.ueberallfernsehen.de/

[38] Riks TV: https://www.rikstv.no/

[39] TP Emitel: http://www.emitel.pl/

[40] TDT - Televisão Digital Terrestre: http://tdt.telecom.pt/
[41] DVB-T Romania: http://www.radiocom.ro

[42] DVB-T Russia: http://www.moscow.rtrs.ru/

[43] Polustelka Slovakia: http://plustelka.sk/

[44] DVB-T Slovenia: http://dvb-t.akos-rs.si/

[45] Emisiona tehnika i veze: http://www.etv.rs/

[46] MTS Antena TV: https://mtsantenatv.rs/kanali. html

[47] Television Digital Terrestre (TDT): www.televisiondigital.es

[48] Boxer TV Sweden: http://www.boxer.se/

[49] SRG SSR idée suisse: https://www.broadcast.ch/de/ startseite/

[50] Digital UK: http://www.digitaluk.co.uk/

[51] Freeview: http://www.freeview.co.uk/ 